\title{
Photodeposition of Pt on Colloidal CdS and CdSe/CdS Semiconductor Nanostructures
}

Gordana Dukovic, Maxwell G. Merkle, James H. Nelson, Steven M. Hughes, and

A. Paul Alivisatos*

Department of Chemistry, University of California, Berkeley and Materials Science Division, Lawrence Berkeley National Laboratory, Berkeley, CA 94720, USA

Semiconductor photocatalysis has been identified as a promising avenue for the conversion of solar energy into environmentally friendly fuels, most notably by the production of hydrogen from water.[1-5] Nanometer-scale materials in particular have attracted considerable scientific attention as the building blocks for light-harvesting applications.[6,7] Their desirable attributes include tunability of the optical properties with size, amenability to relatively inexpensive low-temperature processing, and a high degree of synthetic sophistication leading to increasingly complex and multi-functional architectures. For photocatalysis in particular, the high surface- to- volume ratios in nanoscale materials should lead to an increased availability of carriers for redox reactions on the nanoparticle surface.

Recombination of photoexcited carriers directly competes with photocatalytic activity.[3] Charge separation is often achieved with multi-component heterostructures. An early example is the case of $\mathrm{TiO} 2$ powders functionalized with $\mathrm{Pt}$ and $\mathrm{RuO} 2$ particles, where photoexcited electrons are transferred to $\mathrm{Pt}$ (the reduction site) and holes to $\mathrm{RuO} 2$ (the oxidation site).[8] More recently, many colloidally synthesized nanometer-scale metal-semiconductor heterostructures have been reported.[7,9,10] A majority of these structures are made by thermal methods.[7,10] We have chosen to study photochemical formation of metal-semiconductor heterostructures. The detailed understanding of the mechanisms involved in photodeposition of metals on nanometer-scale semiconductors is necessary to enable a high degree of synthetic control. At the same time, because the results of metal deposition can be directly observed by electron microscopy, it can be used to understand how factors such as nanocrystal composition, shape, carrier dynamics, and surface chemistry influence the photochemical properties of semiconductor nanocrystals.

In this communication, we report on the photodeposition of $\mathrm{Pt}$ on colloidal $\mathrm{CdS}$ and $\mathrm{CdSe} / \mathrm{CdS}$ core/shell nanocrystals. Among the II-VI semiconductors, CdS is of particular interest because it has the correct band alignment for water photolysis[2] and has been demonstrated to be photocatalytically active.[11-16] We have found that the photoexcitation of $\mathrm{CdS}$ and $\mathrm{CdSe} / \mathrm{CdS}$ in the presence of an organometallic Pt precursor leads to deposition of $\mathrm{Pt}$ nanoparticles on the semiconductor surface. Stark differences are observed in the Pt nanoparticle location on the two substrates, and the photodeposition can be completely inhibited by the modification of the semiconductor surface. Our results suggest that tuning of the semiconductor band structure, spatial organization and surface chemistry should be crucial in the design of photocatalytic nanostructures. 
Photodeposition of Pt on CdS Nanorods. The use of CdS powders for photoreduction of Pt salts in aqueous solutions using molecules such as triethylamine (TEA) as hole scavengers was reported as early as the 1980s.[17-19] We have adapted a similar three-component reaction scheme with reactants chosen specifically for their optical properties and solubility in toluene. The reaction mixture contained colloidal CdS nanorods (Fig. 1a), (1,5cyclooctadiene)dimethylplatinum(II) $\left(\left(\mathrm{CH}_{3}\right)_{2} \mathrm{PtCOD}\right)$ as the platinum source and an excess of a tertiary amine (such as TEA and diisopropylethylamine (DIPEA)). An excitation wavelength of $458 \mathrm{~nm}$ was chosen to ensure that $\mathrm{CdS}$ is the only light-absorbing component, thus preventing homogeneous nucleation of platinum (Fig. 1d).
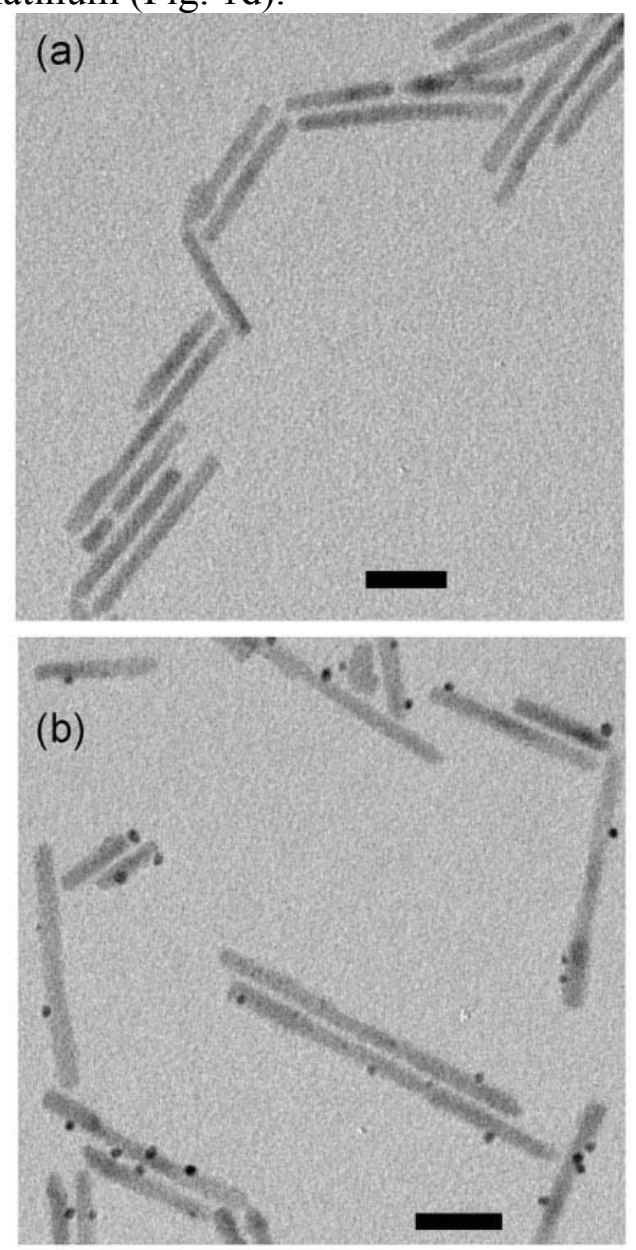

(c)
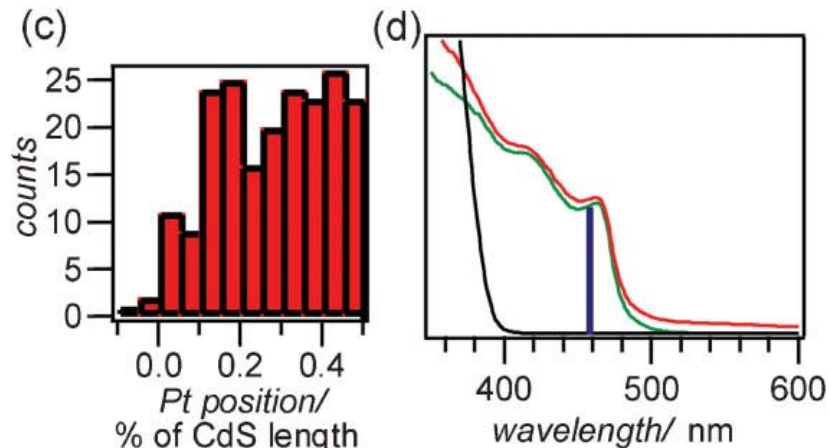

Figure 1. Photodeposition of Pt on CdS nanorods. a) TEM images of CdS nanorods before irradiation and $b$ ) of the photodeposition product. After exposure to light, nanoparticles appear along the length of the nanorods. Scale 
bar=20 nm. c) Histogram of Pt nanoparticle position as a function of percentage of CdS nanorod length, showing random nanoparticle placement. d) Absorption spectra of $\left(\mathrm{CH}_{3}\right)_{2} \mathrm{PtCOD}$ (black), CdS nanorods (green), and the photoreaction product (red). Laser wavelength is shown in blue. Note the appearance of a continuous absorption feature above $500 \mathrm{~nm}$ after photoreaction.

When the reaction mixture is irradiated under an inert atmosphere, the solution turns from translucent yellow to translucent brown. This change is reflected in the absorption spectrum (Fig. 1d) as a new, continuous extinction feature at photon energies below $500 \mathrm{~nm}$. In the absorption spectra of Pt nanoparticles, this extinction feature corresponds to the tail of the surface plasmon, which peaks around $250 \mathrm{~nm}$.[20-23] The change in the absorption spectra is accompanied by the quenching of CdS fluorescence. Transmission electron microscopy (TEM) shows the formation of heterostructures consisting of small nanoparticles positioned along the length of the CdS nanorods (Fig. 1b). The average diameters of the nanoparticles range from 1.5 to $2.7 \mathrm{~nm}$, depending on the reaction conditions. Statistical analysis (Fig. 1c) points to random distribution of nanoparticle positions along the nanorod length, with no preference for rod ends. This is in contrast to metal-chalcogenide heterostructures synthesized by thermal methods, where metal deposition often occurs preferentially on the nanorod ends.[24-27]

Control experiments show that the exclusion of any single reaction component (light, $\mathrm{CdS},\left(\mathrm{CH}_{3}\right)_{2} \mathrm{PtCOD}$, amine) results in no observable nanoparticle formation. When the reaction mixture is stored in dark after irradiation, no further observable Pt deposition occurs. Likewise, storing the reaction mixture in the dark before irradiation does not increase deposition yield. The latter two experiments show that light is a necessary "reactant" for each deposition event, i.e., it does not merely initiate the deposition. Measurements of $\mathrm{CdS}$ nanorod dimensions before and after the photoreaction show no evidence of photoinduced corrosion.

Structural Characterization of CdS/Pt Nanoheterostructures. Figure 2 shows three highresolution TEM images of nanoparticles on CdS nanorods where both the (001) planes of hexagonal $\mathrm{CdS}$ and the crystal planes of the nanoparticles are resolved. The $0.22 \mathrm{~nm}$ crystal plane spacing in the nanoparticles corresponds to the spacing of (111) planes in face-centered cubic platinum. None of the images show evidence of epitaxial growth of Pt on CdS, and the angle of (111) planes of Pt and (001) planes of hexagonal CdS varies from image to image. This is similar to the nonepitaxial growth previously observed for $\mathrm{Au} / \mathrm{CdS}$ and $\mathrm{Au} / \mathrm{CdSe}$ nanoheterostructures, which has been attributed to lattice mismatch between the two materials.[24,26]

Photochemical formation of $\mathrm{Pt} / \mathrm{CdS}$ heterostructures produces a signature in the X-ray diffraction (XRD) patterns of the product. Figure 2 compares the XRD patterns of the reaction mixture before and after irradiation. Before irradiation, the pattern corresponds to hexagonal (wurtzite) $\mathrm{CdS}$, whereas the pattern of the photoreaction product has a new peak corresponding to the diffraction of (111) planes of face-centered cubic platinum. Accurate determination of the Pt crystal size using the Debye-Scherrer method is difficult due to overlapping peaks, but the peak width is roughly consistent with a particle size between 2 and $3 \mathrm{~nm}$. 

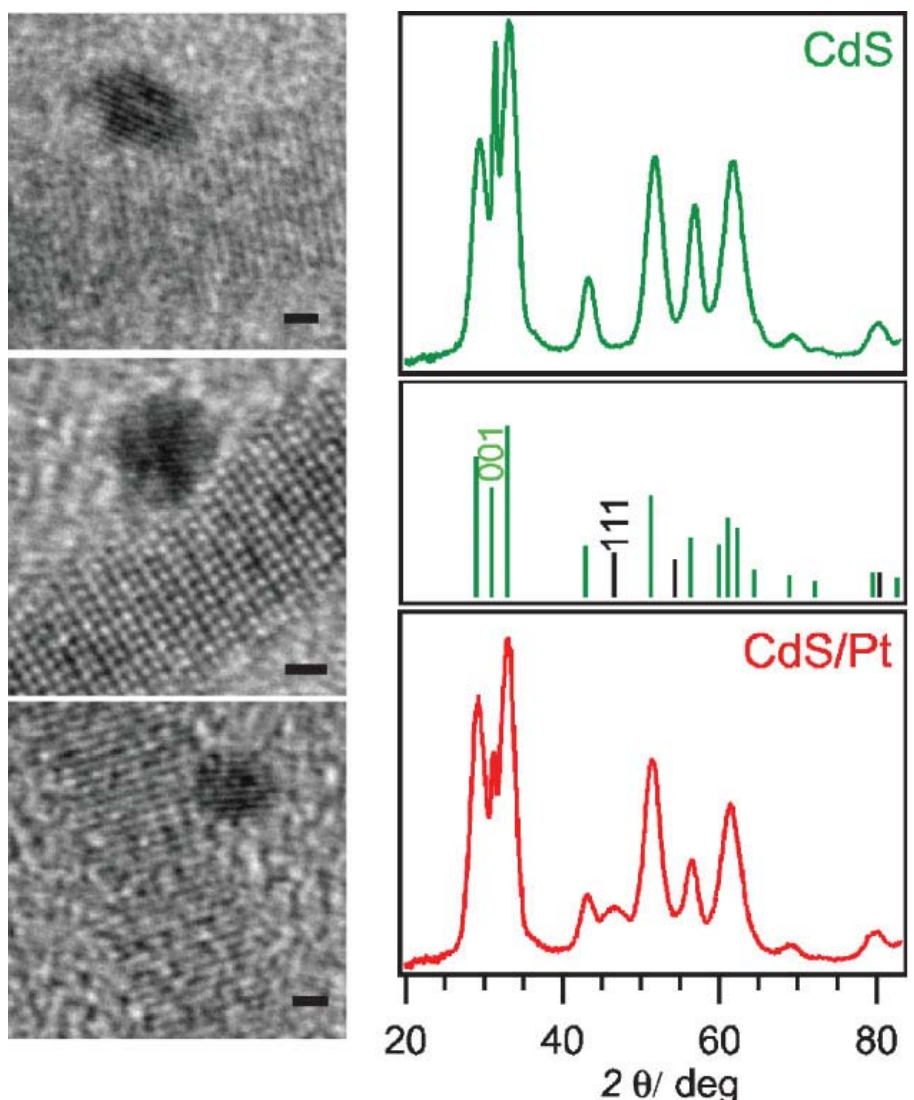

Figure 2. Structural characterization of the photodeposition product. (left) High-resolution TEM images showing lattice planes of $\mathrm{Pt}$ and hexagonal CdS. The metal growth does not appear to be epitaxial. Scale bar=1 nm. (right) XRD patterns of CdS nanorods (top, green) and photoreaction product (bottom, red). Published diffraction peaks for CdS (green) and Pt (black) are shown in the middle panel. Note the appearance of the Pt (111) peak in the photoreaction product.

Pt Nanoparticle Distribution and Reaction Time. Figure 3 illustrates how the distribution of Pt nanoparticles along CdS nanorods develops over time. The histogram in Figure 3a shows that the number of $\mathrm{Pt}$ nanoparticles on a $\mathrm{CdS}$ nanorod increases from $\mathrm{t}=30 \mathrm{~min}$ (distribution peaks at zero) to $\mathrm{t}=60 \mathrm{~min}$ (peaks at $1 \mathrm{Pt}$ nanoparticle), but remains relatively constant thereafter. Similar information is conveyed in table in Figure 3a, which shows that the average length of CdS per Pt nanoparticle decreases significantly between 30 and $60 \mathrm{~min}$. By contrast, the average Pt nanoparticle diameter continues to increase beyond the first hour (see table in Fig. 3a). Figure 3b shows that the Pt yield, determined by elemental analysis, increases linearly with time up to at least $4 \mathrm{~h}$. These observations indicate that, after an initial period of nucleation, Pt deposition proceeds via nanoparticle growth with minimal nucleation of new $\mathrm{Pt}$ nanoparticles. This is consistent with the expectation that the photoexcited electrons quickly decay from the semiconductor valence band to the metal,[28-31] where the subsequent reduction events should occur.

Figure 3c shows how the number of Pt nanoparticles on a $\mathrm{CdS}$ nanorod varies with the nanorod length at $\mathrm{t}=120 \mathrm{~min}$. While on average a longer nanorod may be more likely to have more Pt nanoparticles, the distribution is extremely broad. Most notably, many nanorods, even some longer than $50 \mathrm{~nm}$, do not show any evidence of Pt deposition. Such a varied distribution 
of Pt nanoparticles suggests that the deposition of the metal occurs because of the presence of particular surface sites, which are present to a greater extent in some nanorods and to a lesser extent in others. Examples of such sites would include surface defects or sites of incomplete surface passivation that could serve as carrier traps. The example below illustrates a contrasting case of Pt nanoparticle location.
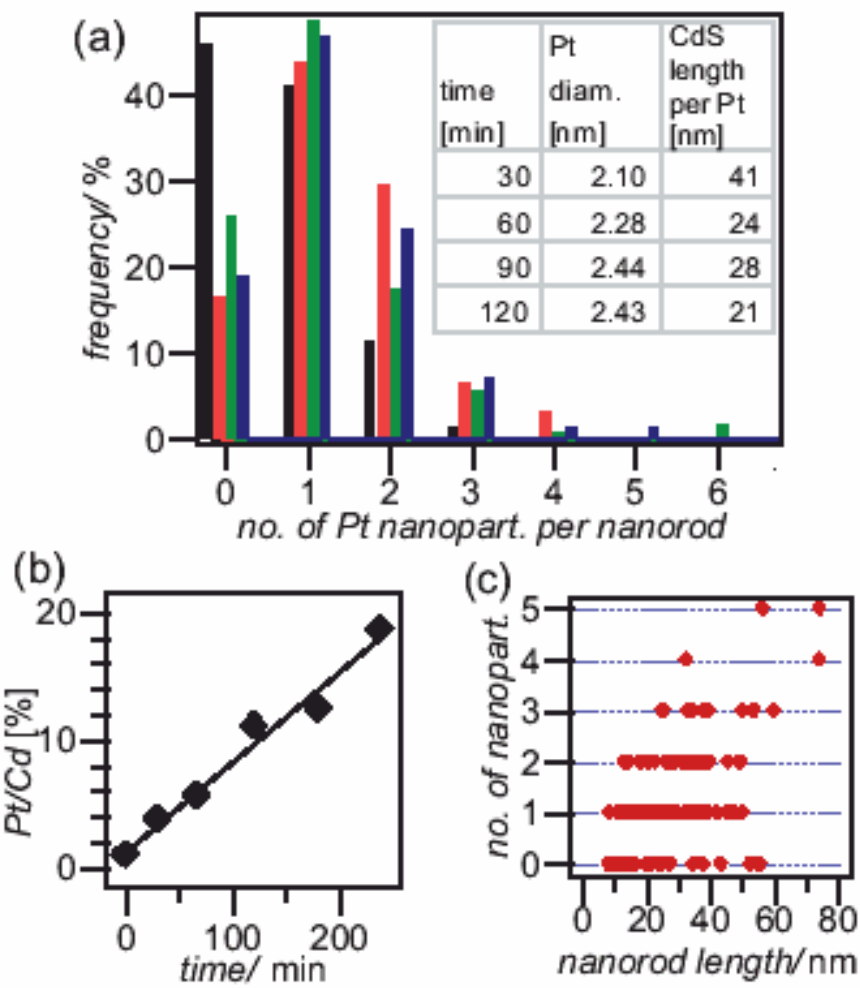

Figure 3. Distribution of Pt nanoparticles on CdS nanorods. a) Histogram of number of Pt nanoparticles on each $\mathrm{CdS}$ nanorod as a function of reaction time for $30 \mathrm{~min}$ (black), $60 \mathrm{~min}$ (red), $90 \mathrm{~min}$ (green), and $120 \mathrm{~min}$ (blue). Sample size for each dataset was greater than 100 nanorods. Inset: Pt nanoparticle diameter and average length of $\mathrm{CdS}$ nanorod per Pt nanoparticle. Pt particles are formed within the first hour and grow by further deposition of $\mathrm{Pt}$ on the existing metal sites. b) Pt yield, expressed as the $\mathrm{Pt} / \mathrm{Cd}$ ratio in the sample, as a function of reaction time, showing that Pt deposition proceeds at a constant rate. (c) Number of Pt nanoparticles on a CdS nanorod as a function of the nanorod length for $\mathrm{t}=120 \mathrm{~min}$. Note that even the longer nanorods can show no Pt deposition.

Photodeposition of Pt on CdSe/CdS Nanoheterostructures. Figure 4 shows the result of photodeposition of $\mathrm{Pt}$ on core/shell heterostructures consisting of a CdSe core and a CdS shell that extends into a nanorod shape.[32-34] The position of the CdSe core can be identified in most heterostructures (Fig. 4a) as a bulge near one end of the nanorod. There are two notable differences between the photodeposition products for these heterostructures when compared to CdS nanorods: (i) most heterostructures have one Pt nanoparticle. Specifically, 19\% of the heterostructures have no nanoparticles, $75 \%$ have one nanoparticle, and $6 \%$ have two nanoparticles. (ii) Pt deposition occurs near the CdSe core (Fig. 4b). It is not clear at this time whether the Pt deposition near the core is a consequence of electron or hole localization at the $\mathrm{CdSe}$ core, or whether it is related to the nanocrystal surface. Experiments to address this issue are currently in progress. 

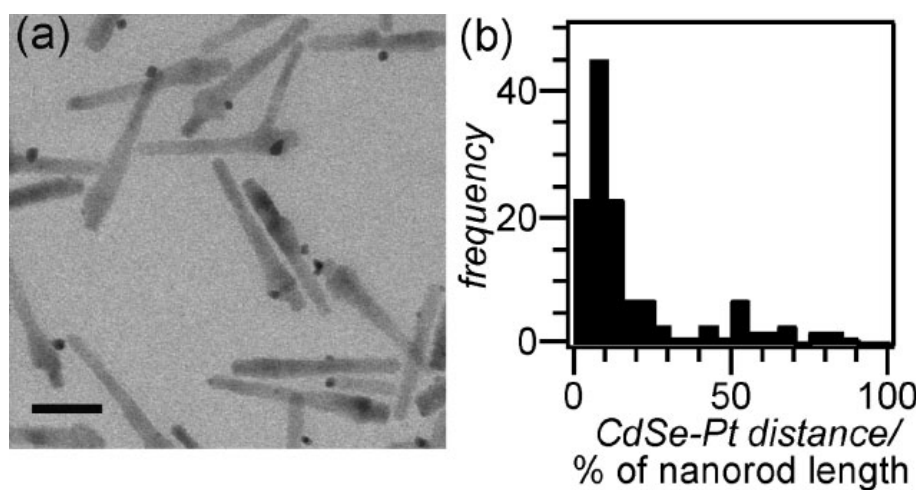

Figure 4. Photodeposition of $\mathrm{Pt}$ on $\mathrm{CdSe} / \mathrm{CdS}$ core/shell nanorods. a) TEM image of the resulting heterostructures. Scale bar=20 nm. Most heterostructures only have one Pt nanoparticle located near the core. b) Distribution of Pt nanoparticle positions along the core/shell nanorods, quantified as the distance between the center of the CdSe core and the center of $\mathrm{Pt}$ nanoparticle as a fraction of the total nanorod length. Sample size was $152 \mathrm{CdSe} / \mathrm{CdS}$ heterostructures.

Photodeposition Dependence on Irradiation Power and Reactant Concentrations. Figure 5a illustrates how the yield of Pt deposited on CdS nanorods varies with irradiation power. The increase in yield with laser power at lower powers is followed by saturation above $25 \mathrm{~mW}$. An irradiation power of $25 \mathrm{~mW}$ corresponds to an average excitation frequency of approximately 1 photon $\mathrm{ms}^{-1}$ per CdS nanorod. Under these conditions, we estimate the quantum yield for the $\mathrm{Pt}$ deposition to be on the order of $10^{-4} \mathrm{Pt}$ atoms per photon. The fluorescence quantum yield for the $\mathrm{CdS}$ reactant is only $\sim 10^{-3}$, indicating that nonradiative processes play an important role and could limit the availability of photoexcited carriers and thus contribute to a low quantum yield for Pt deposition.
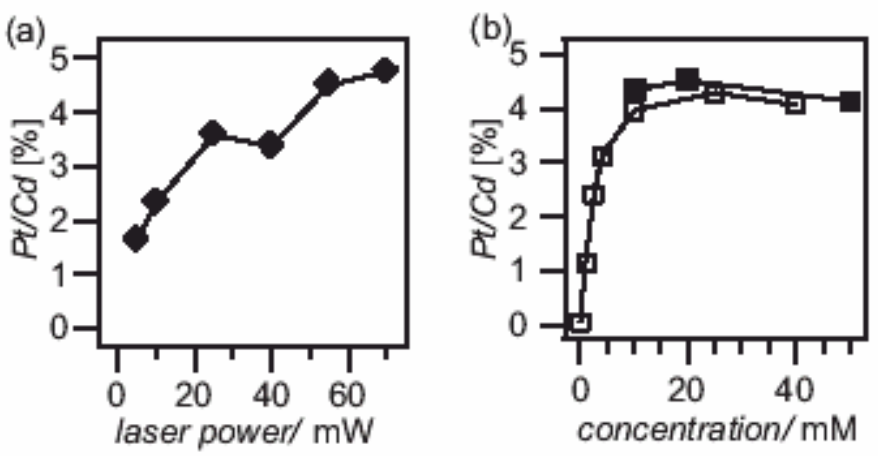

Figure 5. Dependence of Pt-to-Cd molar ratio on experimental parameters: (a) Pt conversion as a function of laser power. $[\mathrm{CdS}]=10 \mathrm{mM},[(\mathrm{CH} 3) 2 \mathrm{PtCOD}]=10 \mathrm{mM}$. b) $\mathrm{Pt} / \mathrm{Cd}$ as a function of concentrations of $\mathrm{CdS}$ units (filled squares) and $\left(\mathrm{CH}_{3}\right)_{2} \mathrm{PtCOD}$ (open squares). When the concentration of one reactant is varied, the other is held constant at $10 \mathrm{mM}$.

Saturation of the yield of deposited $\mathrm{Pt}$ at higher laser powers indicates that increasing the excitation frequency above 1 photon $\mathrm{ms}^{-1}$ fails to increase the rate of $\mathrm{Pt}$ deposition, which suggests that a slow step limits the deposition rate. Such a slow step could be the reduction of $\left(\mathrm{CH}_{3}\right)_{2} \mathrm{PtCOD}$, possibly due to a complex multielectron mechanism that requires an energetically unfavorable accumulation of multiple electrons on a small metal nanoparticle. Alternatively, the reaction involving amine could be the rate-determining step. Some evidence for the latter is presented later in the text. 
Figure 5b shows how the yield of Pt deposition depends on the concentration of CdS and $\left(\mathrm{CH}_{3}\right)_{2} \mathrm{PtCOD}$. [CdS] refers to the concentration of CdS units, not $\mathrm{CdS}$ nanocrystals. At low $\left(\mathrm{CH}_{3}\right)_{2} \mathrm{PtCOD}$ concentrations, the yield of the deposited metal is limited by the precursor concentration. Pt conversion plateaus at $10 \mathrm{mM}\left(\mathrm{CH}_{3}\right)_{2} \mathrm{PtCOD}$, the concentration adopted as the standard condition for the other experiments described in this work. At this concentration, we estimate the collision frequency between a $\mathrm{CdS}$ nanorod and $\left(\mathrm{CH}_{3}\right)_{2} \mathrm{PtCOD}$ molecules to be $10^{5}$ $\mathrm{ms}^{-1}$. In contrast to this plateauing behavior, the $\mathrm{Pt} / \mathrm{Cd}$ ratio remains constant with $[\mathrm{CdS}]$, i.e., the amount of deposited Pt scales linearly with the number of CdS nanorods in solution, while the amount of Pt deposited on each nanorod remains constant. This observation was confirmed by a quantitative analysis of the TEM images of the heterostructures. The limiting role of the amount of $\mathrm{CdS}$ in the solution is consistent with the existence of a slow process that limits the rate of $\mathrm{Pt}$ deposition on each CdS nanorod.

Photodeposition Dependence on the Amine. The photodeposition of $\mathrm{Pt}$ on $\mathrm{CdS}$ shows a strong dependence on the nature of the amine used. Highest yields are observed with bulky tertiary amines such as DIPEA and TEA. Comparison of octylamine, dioctylamine, and trioctylamine reveals no photodeposition for the primary amine, very little for the secondary, and the most for trioctylamine. A possible reason for this is that the bulky amines may not be able to bind easily to the nanocrystal surface due to steric hindrance. Primary amines, on the other hand, are thought to passivate the surfaces of chalcogenide nanocrystals, as evidenced by an increase in fluorescence quantum yield following amine treatment.[35,36] In fact, when CdS nanorods are transferred from toluene to octylamine, the photodeposition of $\mathrm{Pt}$ is completely inhibited, despite the presence of $\left(\mathrm{CH}_{3}\right)_{2} \mathrm{PtCOD}$ and TEA. This observation is consistent with the idea that the photodeposition requires specific sites, which are now blocked by the interaction of the $\mathrm{CdS}$ nanorod surface with octylamine.

Furthermore, the photodeposition yield of Pt varies significantly when different tertiary amines are used. For example, the yield is approximately two times greater when DIPEA is used instead of TEA, all other conditions being equal. The major difference between these two amines is steric, with DIPEA having bulkier alkyl chains. The observed difference in the yield of deposited Pt suggests that the step involving the amine, be it hole-scavenging (charge transfer) or a more complex reaction, may control the photodeposition rate.

Conclusions and Outstanding Questions. We have characterized the photodeposition of Pt on colloidally synthesized $\mathrm{CdS}$ and $\mathrm{CdSe} / \mathrm{CdS}$ nanorods in an organic solvent. Visible light irradiation of $\mathrm{CdS}$ in the presence of $\left(\mathrm{CH}_{3}\right)_{2} \mathrm{PtCOD}$ and tertiary amines results in deposition of $\mathrm{Pt}$ nanoparticles along the $\mathrm{CdS}$ surface to create metal-semiconductor heterostructures. The placement of Pt deposits on CdS is highly heterogeneous with the number of Pt nanoparticles on each $\mathrm{CdS}$ nanorod ranging from 0 to 6 . By contrast, most $\mathrm{CdSe} / \mathrm{CdS}$ core/shell nanorods feature only one metal nanoparticle located near the CdSe core. Pt deposition is inhibited in octylaminetreated CdS nanorods. These results point to the importance of the nanocrystal surface chemistry, as well as band structure, in determining the photodeposition outcome. After nucleation events at the specific sites, the metal deposits on the existing Pt nanoparticles. Metal deposition occurs slowly and the rate does not increase substantially with excitation frequencies above 1 photon $\mathrm{ms}^{-1}$ per CdS nanorod, suggesting the importance of a slow rate-limiting step. Whether the slow 
rate is due to inherently slow oxidation or reduction steps, fast back-reactions, or inaccessibility of the CdS nanocrystal surface remains to be determined. In our future work, we plan to characterize the oxidation and reduction reactions and identify their products, to understand how charge carrier dynamics influence CdS photochemistry, and to investigate the role of the nanocrystal surface and its accessibility. A more detailed understanding of this system should provide insights useful for photocatalysis at the nanoscale, as well as allow for the degree of control that would develop photochemistry of semiconductor nanocrystals into a synthetic tool.

\section{Experimental}

Synthesis of Semiconductor Nanocrystals: CdS nanorod synthesis was adapted from a previously published procedure [37], with a slight modification of surfactant and reactant amounts. The amounts were: $3.3 \mathrm{~g}$ of tri-n-octylphosphine oxide (TOPO; Sigma-Aldrich, Reagent- Plus1, 99\%), $1.08 \mathrm{~g}$ of n-octadecylphosphonic acid (ODPA; PCI Synthesis, 9 Opportunity Way, Newburyport, MA01950, 978-463-4853, recrystallized from hexane/ethanol), $35 \mathrm{mg}$ of propylphosphonic acid (PPA; Sigma-Aldrich, 95\%), 207mg of CdO (Sigma-Aldrich, 99.99p\%), 2 g of tri-n-octylphosphine (TOP; Strem, 97\%), and $0.645 \mathrm{~g}$ of TOP:S (1:1 molar ratio). Nanocrystal growth was allowed to proceed at $3158 \mathrm{C}$ for $45 \mathrm{~min}$. CdS nanocrystals were precipitated from the cooled reaction mixture with toluene and acetone. Purification by precipitation from chloroform/octylamine/acetone mixture (approx. 5:2:5 ratio by volume) was repeated twice under an inert atmosphere. The nanocrystals were then dissolved in hexane and remaining impurities were precipitated slowly. Finally, the product was transferred to toluene by precipitation with isopropanol. The resulting solution consisted of mostly nanorods with diameters of $4.2-0.4 \mathrm{~nm}$ and lengths ranging from 8 to $81 \mathrm{~nm}$. CdSe/CdS nanoheterostructures were synthesized as previously published [32], Purification was carried out as described above. Cd concentration was determined by elemental analysis (see below).

Photodeposition of Pt: Photodeposition of Pt was carried out under argon in sealed borosilicateNMRtubes of $0.3 \mathrm{~mm}$ diameter. The standard deposition solution included $5.6 \mathrm{~mL}$ (50fold excess) of TEA (Sigma-Aldrich,_99.5\%) (or molar equivalent of other amines), $40 \mathrm{~mL}$ of $19 \mathrm{mM}$ CdS solution in toluene, and $40 \mathrm{~mL}$ of $20 \mathrm{mM}$ (1,5-cyclooctadiene)dimethylplatinum(II) $\left(\left(\mathrm{CH}_{3}\right)_{2} \mathrm{PtCOD}\right.$; Aldrich, 97\%). Photon source was the $458 \mathrm{~nm}$ line of an Ar-ion laser (Lexar Laser, Inc., Model 95 Ion Laser) with the beam spread to _ $1 \mathrm{~cm}$ diameter to ensure even illumination. Under standard photodeposition conditions, laser power was $100 \mathrm{~mW}$, with 50\% of the area of the beam taken up by the sample.

Characterization of Metal-Semiconductor Heterostructures: Absorption spectra of samples diluted in toluene were recorded on an Agilent $8453 \mathrm{UV}$-vis spectrophotometer. Lowmagnification and high-resolution TEM images were acquired using a 200kV LaB6 FEI Tecnai G2 20 HRTEM, equipped with a Super TWIN lens. Images were analyzed using ImagePro software (Media Cybernetics, Inc.). Powder XRD characterization was carried out with a GADDS Hi-Star D8 diffractometer (Bruker) using CoKa radiation $\left(1.790 \mathrm{~A}^{\circ}\right.$ ) and a general area detector. Samples were prepared by deposition on a quartz plate, and the diffraction of the quartz was subtracted from the XRD signal. Accumulation time for each sample was 60 min $(30 \mathrm{~min}$ per frame). Experimental XRD patterns were compared with those published in the Joint 
Committee of Powder Diffraction Standards PDF database for bulk materials (CdS: no. 41-1049; Pt: no. 04-0802). Semiconductor concentrations and Pt yields were determined by elemental analysis performed on a Perkin Elmer Optima 3000 DV ICP-OES instrument. To minimize signal overlap, the optical emission lines used were $226.5 \mathrm{~nm}$ for $\mathrm{Cd}$ and $265.9 \mathrm{~nm}$ for Pt. Signal intensities were calibrated using Cd and Pt ICP standards (Sigma-Aldrich). To minimize the interference of the unreacted $\mathrm{Pt}$ precursor in ICP, photodeposition products were first precipitated twice from a toluene/isopropanol mixture. The material was then digested with a mixture of $\mathrm{HNO} 3$ and $\mathrm{HCl}$ for $8 \mathrm{~h}$ and then diluted to $5.00 \mathrm{~mL}$ withMillipore water.

Acknowledgements: We thank B. F. Sadtler, J. S. Owen, M. Steigerwald, and L. E. Brus for fruitful discussions. This work was supported in part by AFOSR Grant No. FA9550-06-1-0488 and by the Director, Office of Science, Office of Basic Energy Sciences, of the US Department of Energy under Contract No. DE-AC02-05CH11231.

\section{References:}

[1] A. J. Bard, M. A. Fox, Acc. Chem. Res. 1995, 28, 141.

[2] L. A. Harris, R. H. Wilson, Annu. Rev. Mater. Sci. 1978, 8, 99.

[3] A. L. Linsebigler, G. Q. Lu, J. T. Yates, Chem. Rev. 1995, 95, 735.

[4] A. J. Nozik, Annu. Rev. Phys. Chem. 1978, 29, 189.

[5] M. Tomkiewicz, H. Fay, Appl. Phys. 1979, 18, 1.

[6] S. E. Gledhill, B. Scott, B. A. Gregg, J. Mater. Res. 2005, 20, 3167.

[7] P. V. Kamat, J. Phys. Chem. C 2007, 111, 2834.

[8] D. Duonghong, E. Borgarello, M. Graetzel, J. Am. Chem. Soc. 1981, 103, 4685.

[9] T. Wu, Y. Li, M. Chu, in: Handbook of Photochemistry and Photobiology, Vol. 1, Inorganic Photochemistry (Ed: H.S. Nalwa,), American Scientific Publishers, Stevenson Ranch, CA 2003, 249.

[10] P. D. Cozzoli, T. Pellegrino, L. Manna, Chem. Soc. Rev. 2006, 35, 1195.

[11] B. R. Eggins, J. T. S. Irvine, E. P. Murphy, J. Grimshaw, J. Chem. Soc, Chem. Commun. $1988,1123$.

[12] A. Kumar, S. Kumar, J. Phys. Org. Chem. 1998, 11, 277.

[13] T. Shiragami, H. Ankyu, S. Fukami, C. Pac, S. Yanagida, H. Mori, H. Fujita, J. Chem. Soc. Faraday Trans. 1992, 88, 1055.

[14] T. Shiragami, S. Fukami,Y. J.Wada, S. Yanagida, J. Phys. Chem. 1993, 97, 12882.

[15] T. Shiragami, C. Pac, S. Yanagida, J. Phys. Chem. 1990, 94, 504.

[16] H. B. Yin, Y. Wada, T. Kitamura, S. Yanagida, Environ. Sci. Technol. 2001, 35, 227.

[17] A. J. Frank, Z. Goren, I. Willner, J. Chem. Soc, Chem. Commun. 1985, 1029.

[18] J. R. Harbour, R. Wolkow, M. L. Hair, J. Phys. Chem. 1981, 85, 4026.

[19] J. F. Reber, M. Rusek, J. Phys. Chem. 1986, 90, 824.

[20] C. W. Chen, M. Akashi, Langmuir 1997, 13, 6465.

[21] J. A. Creighton, D. G. Eadon, J. Chem. Soc, Faraday Trans. 1991, 87, 3881.

[22] J. C. Huang, Z. L. Liu, X. M. Liu, C. B. He, S. Y. Chow, J. S. Pan, Langmuir 2005, 21, 699.

[23] C. Yee, M. Scotti, A. Ulman, H. White, M. Rafailovich, J. Sokolov, Langmuir 1999, 15, 4314.

[24] T. Mokari, E. Rothenberg, I. Popov, R. Costi, U. Banin, Science 2004, 304, 1787. 
[25] T. Mokari, C. G. Sztrum, A. Salant, E. Rabani, U. Banin, Nat. Mater. 2005, 4, 855.

[26] A. E. Saunders, I. Popov, U. Banin, J. Phys. Chem. B 2006, 110, 25421.

[27] S. E. Habas, P. D. Yang, T. Mokari, J. Am. Chem. Soc. 2008, 130, 3294.

[28] P. D. Cozzoli, E. Fanizza, R. Comparelli, M. L. Curri, A. Agostiano, D. Laub, J. Phys. Chem. B 2004, 108, 9623.

[29] T. Hirakawa, P. V. Kamat, J. Am. Chem. Soc. 2005, 127, 3928.

[30] V. Subramanian, E. E. Wolf, P. V. Kamat, J. Am. Chem. Soc. 2004, 126, 4943.

[31] A. Wood, M. Giersig, P. Mulvaney, J. Phys. Chem. B 2001, 105, 8810.

[32] D. V. Talapin, J. H. Nelson, E. V. Shevchenko, S. Aloni, B. Sadtler, A. P. Alivisatos, Nano Lett. 2007, 7, 2951.

[33] J. Muller, J. M. Lupton, P. G. Lagoudakis, F. Schindler, R. Koeppe, A. L. Rogach, J. Feldmann, D. V. Talapin, H.Weller, Nano Lett. 2005, 5, 2044.

[34] D. V. Talapin, R. Koeppe, S. Gotzinger, A. Kornowski, J.M.Lupton, A. L. Rogach, O. Benson, J.Feldmann,H.Weller,NanoLett. 2003, 3, 1677.

[35] G. Kalyuzhny, R. W. Murray, J. Phys. Chem. B 2005, 109, 7012.

[36] D. V. Talapin, A. L. Rogach, A. Kornowski, M. Haase, H. Weller, Nano Lett. 2001, 1, 207.

[37] R. D. Robinson, B. Sadtler, D. O. Demchenko, C. K. Erdonmez, L. W. Wang, A. P. Alivisatos, Science 2007, 317, 355.

\section{DISCLAIMER}

This document was prepared as an account of work sponsored by the United States Government. While this document is believed to contain correct information, neither the United States Government nor any agency thereof, nor The Regents of the University of California, nor any of their employees, makes any warranty, express or implied, or assumes any legal responsibility for the accuracy, completeness, or usefulness of any information, apparatus, product, or process disclosed, or represents that its use would not infringe privately owned rights. Reference herein to any specific commercial product, process, or service by its trade name, trademark, manufacturer, or otherwise, does not necessarily constitute or imply its endorsement, recommendation, or favoring by the United States Government or any agency thereof, or The Regents of the University of California. The views and opinions of authors expressed herein do not necessarily state or reflect those of the United States Government or any agency thereof or The Regents of the University of California. 